\title{
EFFECT OF THICKNESS VARIATION ON THE TRANSLUCENCY OF TWO RECENT HIGH TRANSLUCENT MONOLITHIC ZIRCONIA CERAMICS
}

\author{
Ahmed M. Alamledin, ${ }^{*}$ Tamer E. Shokry, ${ }^{* *}$ Ahmed Y. El Kouedi ${ }^{* *}$
}

\begin{abstract}
Objective: The objective of this study was to evaluate the effect of thickness change on the translucency of two recent monolithic zirconia dental ceramics used at different thicknesses. Materials and methods: A total of 60 disk-shaped specimens were prepared from two high-translucent tetragonal zirconia (Zolid ht+) and ultra-translucent cubic zirconia (Zolid fx), and divided equally into two groups according to material, each group with further subdivided into 3 subgroups according to thickness 0.5 , 1 , and $1.5 \mathrm{~mm}(\mathrm{n}=10)$. A spectrophotometer was used to assess the CIE $\mathrm{L}^{*}, \mathrm{a}^{*}$, and $\mathrm{b}^{*}$ for each thickness of the two zirconia ceramics. The Translucency Parameter (TP) was calculated. 1-way ANOVA and 2-way ANOVA statistical analysis of variance were performed $(\alpha=.05)$. Results. A statistically significant higher mean TP value was recorded with the ultra-translucent cubic zirconia group compared to that of high-translucent tetragonal zirconia regardless of thickness $(\mathrm{P}=0.008 *<0.05)$. Thickness had a significant effect on the translucency parameter of the two zirconia ceramics. Within group comparisons showed that for each of the two materials, the $0.5 \mathrm{~mm}$ thickness recorded the statistically significant highest mean TP value, followed by the $1 \mathrm{~mm}$ subgroup, whereas the statistically significant lowest mean TP value was recorded for the $1.5 \mathrm{~mm}$ subgroup. Conclusions. Within the limitations of this study, it was found that material type and thickness had a significant effect on the translucency of high translucent monolithic zirconia.
\end{abstract}

KEYWORDS: thickness variation, translucent zirconia, translucency

\section{INTRODUCTION}

All ceramic restorations have witnessed a plethora in clinical use after being proven to be a successful replacement of their older metalceramic predecessor ${ }^{(1,2)}$. This success has enabled clinicians to produce higher esthetics with their all ceramic reconstructions ${ }^{(3)}$. Zirconia has emerged as the center of this all ceramic clinical interest due to their superior mechanical properties ${ }^{(4)}$. Many improvements of monolithic zirconia have been made which enabled their use in decreased thicknesses. Thickness is a strong determinant of success in all ceramic restorations. The thickness at which monolithic zirconia can resist high occlusal loads went down to a thickness as low as $0.5 \mathrm{~mm}$ both axially and occlusally ${ }^{(5,6)}$, even when used as a single tooth full coverage fixed dental restoration -i.e. crown- in the molar region ${ }^{(7)}$. With this thickness decrease, the translucency of the ceramic restoration could be altered ${ }^{(8)}$. However, in clinical practice, thickness control is multifactorial, and needs a compromise between contours, tooth alignment adjustment and numerous other factors ${ }^{(9)}$.

*Assistant Lecturer and PhD student, Department of Fixed Prosthodontics, Faculty of Dental Medicine, Al-Azhar University, Cairo, Egypt

${ }^{* *}$ Professor, Department of Fixed Prosthodontics, Faculty of Dental Medicine, Al-Azhar University, Cairo, Egypt.

- Corresponding author: ahmed.alameldin@azhar.edu.eg

DOI: 10.21608 /ajdsm.2020.25066.1012 
Translucency plays an important role in the final esthetic outcome of a restoration ${ }^{(10)}$. The advent of enhanced translucency in newer generations of monolithic zirconia has made deciding the degree of translucency anticipated from a zirconia restoration paramount. The polycrystalline nature of zirconia controls its translucency to a large extent. Like all polycrystalline materials, their optical properties depend, to a large degree, on their microstructure ${ }^{(11)}$. Furthermore, zirconia crystals scatter light due to their crystallinity ${ }^{(12)}$. All improvements in the translucency of zirconia was directed towards the decrease of this light scattering and improving light passage through a zirconia structure. However, assessing translucency is critical. Objective and quantitative assessment could be made by the CIELab system ${ }^{(13)}$. Spectrophotometers have been used to assess translucency instrumentally using the CIELab coordinates ${ }^{(14)}$. According to the CIELab system, the translucency of dental restorative materials, including ceramics, has been evaluated using the Translucency Parameter (TP) ${ }^{(15)}$. TP is "the color difference of a material of a uniform thickness in optical contact with ideal white and black backgrounds" ${ }^{(16,17)}$.

Partially-stabilized tetragonal zirconia (PSZ) is one of the most heavily-used ceramics used for the construction of fixed dental prostheses. The welldocumented transformation toughening mechanism has granted the material the term "ceramic steel". Even though their translucency enabled their use as monolithic restorations, it was far below the translucency obtained by its more translucency competitor glass ceramics ${ }^{(18)}$. Fully-stabilized cubic zirconia (FSZ) has been developed to overcome the translucency challenge observed with older PSZ ${ }^{(19)}$. Unlike the metastable nature of tetragonal zirconia, increasing stabili zing oxides' concentration to a critical limit has allowed for making the cubic phase prevalent in dental zirconia, known as cubic or fully-stabilized zirconia. The cubic nature FSZ enhances its translucency ${ }^{(20)}$. On the meantime, because the cubic phase in this class of zirconia is fully-stable, this material does not possess the transformation toughening mechanism, which its predecessor, partially-stabilized tetragonal zirconia, was famous for ${ }^{(21)}$. This limited the use of this type of monolithic zirconia to a set of particular clinical situations. Little is known about the interaction between thickness change and translucency of the newly-developed FSZ compared to PSZ. The hypothesis of this study was that thickness decrease will have a significant effect on the translucency of the two types of monolithic zirconia.

\section{MATERIALS AND METHODS}

Two highly translucent monolithic zirconia materials were used in the study, categorized based on the degree of their stability into: Partiallystabilized high-translucent tetragonal zirconia PSZ (Ceramill ${ }^{\circledR}$ Zolid ht+) (HT group) and Fullystabilized ultra-translucent cubic zirconia FSZ (Ceramill@ Zolid fx) (FX group). A total of 60 rectangular disk-shaped specimens $(10 \times 10 \mathrm{~mm})$ were fabricated from white zirconia blanks in their presintered state of each of the two materials, 30 specimens each. Each of the two groups was further subdivided into three subgroups based on thickness into $0.5,1$, and $1.5 \mathrm{~mm}$ subgroups $(\mathrm{n}=10)$. Cuts were made into the presintered blanks using a linear high precision microtome (Isomet 4000; Buehler) with a diamond disk $20 \mathrm{~cm}$ in diameter and $0.6 \mathrm{~mm}$-thick, running at a speed of $2500 \mathrm{rpm}$ under a continuous water coolant. The integrated cooling system flooded specimens from both sides of the cutting blade. All specimens were cut 20\% larger than the desired dimensions to compensate for the sintering volumetric shrinkage. All disks were $12 \times 12 \mathrm{~mm}$ in the pre-sintered state with an initial thickness of $0.6 \mathrm{~mm}, 1.2 \mathrm{~mm}$. and $1.5 \mathrm{~mm}$ for the $0.5,1$, and $1.5 \mathrm{~mm}$ subgroups, respectively. This enabled obtaining disks with a $10 \times 10 \mathrm{~mm}$ final dimensions at the desired thickness of each of the subgroups. Specimens' dimensions -width and thickness- were confirmed using a digital caliper (Fisher Scientific Traceable Caliper) immediately 
after sectioning in their presintered state, and rechecked after the sintering process to confirm that the desired thickness was obtained.

White presintered zirconia disk-shaped specimens were colored before the sintering stage by dipping into an A2 coloring liquid corresponding to each of the two types of zirconia material used; Ceramill ${ }^{\circledR}$ Coloring Liquid New Formula for PSZ, and Ceramill@ fx Coloring Liquid for FSZ (Amann Girrbach). Specimens were sintered in a zirconia sintering furnace (Ceramill@ Therm 3; Amann Girrbach) at a temperature of $1450{ }^{\circ} \mathrm{C}$ in the Sinter Program 2. In this program, which is recommended by the manufacturer for a single tooth restoration, the sintering process starts at room temperature with a constant heating rate of $720^{\circ} \mathrm{C} / \mathrm{h}\left(12^{\circ} \mathrm{C} / \mathrm{min}\right)$ until it reaches a final sintering temperature of 1450 ${ }^{\circ} \mathrm{C}$ at which holding for 1 hour is maintained. Then, cooling at a rate of $20^{\circ} \mathrm{C} /$ min ensures the temperature to go down to $200{ }^{\circ} \mathrm{C}$ at the end of the sintering cycle. After sintering, all disks were polished by the same operator on one side using a soft Robinson's brush (Abbott-Robinson's soft brush; Keystone Industries) and a zirconia polishing paste (Pearl Surface Z; Kuraray Noritake Dental Inc.). After polishing, all specimens were ultrasonically cleaned in an ultrasonic cleaner (VS350; Silfradent) in an ethyl alcohol bath for 10 minutes, air dried, packed and stored for translucency measurement.

An integrating-sphere reflective light-recording spectrophotometer (RM200QC; X-Rite, NeuIsenburg) was used to assess the color parameters $\mathrm{L}^{*}, \mathrm{a}^{*}$, and $\mathrm{b}^{*}$ on the polished side of each specimen. Measurements were performed at the center of each specimen over a standardized white (CIE L* $\left.=88.81, a^{*}=-4.98, b^{*}=6.09\right)$ and black (CIE L*=7.61, $\left.\mathrm{a}^{*}=0.45, \mathrm{~b}^{*}=2.42\right)$ backgrounds relative to the CIE standard illuminant D65. Specimens were placed at the center of the measuring port and kept in the same position for the two backgrounds. Each specimen was measured three times on each of the two backgrounds, and an average of the three measurements was calculated to obtain one value for each of the color coordinates, for each specimen, on each of the two backgrounds. Translucency was assessed using the Translucency Parameter (TP) calculated based on the following equation:

$$
\mathrm{TP}=\left[(\Delta \mathrm{L} *)^{2}+\left(\Delta \mathrm{a}^{*}\right)^{2}+\left(\Delta \mathrm{b}^{*}\right)^{2}\right]^{1 / 2} .
$$

In this equation, $\Delta \mathrm{L}=\left(\mathrm{L}^{*}{ }_{\mathrm{B}}-\mathrm{L}^{*}{ }_{\mathrm{W}}\right), \quad \Delta \mathrm{a}^{*}=\left(\mathrm{a}^{*}{ }_{\mathrm{B}}{ }^{-}\right.$ $\left.\mathrm{a}^{*}{ }_{\mathrm{W}}\right)$, and $\Delta \mathrm{b}^{*}=\left(\mathrm{b}^{*}{ }_{\mathrm{B}}-\mathrm{b}^{*}{ }_{\mathrm{W}}\right)$, Where "B" and "W" are for the black and white backgrounds, respectively. Each specimen had its mean TP value recorded and tabulated on a computer software (Microsoft Excel spreadsheets, Microsoft) ready for statistical analysis.

Statistical analysis was done using software (Instat software for windows; Graph Pad). A P value of $5 \%$ was the limit of statistical significance $(\mathrm{P}<$ $0.05)$. Continuous variables were expressed as mean +/- Standard Deviation (SD) at a 95\% Confidence interval. After homogeneity of variance and normal distribution of errors have been confirmed using Kolmogorov-Smirnoff test, One-way analysis of variance (ANOVA) was performed to test statistical significance among different thicknesses, followed by Tukey's pairwise test if showed significant. 2-way ANOVA was performed to analyze the effect of material type on the TP regardless of thickness. Power analysis was used to calculate sample size $(\mathrm{n}=10)$, which was proved to be statistically large enough to detect large effect sizes for main effects and pairwise comparisons, with the satisfactory level of power set at $80 \%$ and a $95 \%$ confidence level.

\section{RESULTS}

The total effect of material type on the translucency parameter regardless of thickness was statistically analyzed using two-way ANOVA. It was found that FX group recorded a statistically significant higher mean TP value ( $\mathrm{TP}=12.498 \pm 2.84)$ than that recorded for the HT group, which recorded 
a mean TP value of $(\mathrm{TP}=10.828 \pm 1.81)$ as verified by two-way ANOVA $\left(\mathrm{P}=0.008^{*}<0.05\right)$ (table 1 and figure 1). One-way ANOVA was performed for intra-group comparisons to analyze the effect of thickness change between different thicknesses of each of the two zirconia ceramic materials. It was found that For the FX group, the $0.5 \mathrm{~mm}$ thickness recorded the statistically significant $\left(\mathrm{P}=0.0005^{*}\right.$ $<0.05)$ highest mean $\mathrm{TP}$ value $(\mathrm{TP}=15.51 \pm 1.99)$, followed by the $1 \mathrm{~mm}$ subgroup $(\mathrm{TP}=13.12 \pm 2.374)$, whereas the statistically significant lowest mean TP value was recorded for the $1.5 \mathrm{~mm}$ subgroup $(\mathrm{TP}=10.46 \pm 3.06)$.

TABLE (1) Comparison of translucency parameter (TP) results $(\mathrm{Mean} \pm \mathrm{SD})$ between both groups as a function of material type.

\begin{tabular}{|c|c|c|}
\hline \multicolumn{2}{|c|}{ Variable } & Mean \pm SD \\
\hline \multirow{2}{*}{ Material type } & FX & $12.498^{\mathrm{a}} \pm 2.84$ \\
\cline { 2 - 3 } & HT & $10.828^{\mathrm{b}} \pm 1.81$ \\
\hline Statistics & P value & $0.008^{*}$ \\
\hline
\end{tabular}

*; statistically significant $(p<0.05)$

Different letters denote statistically significant difference.

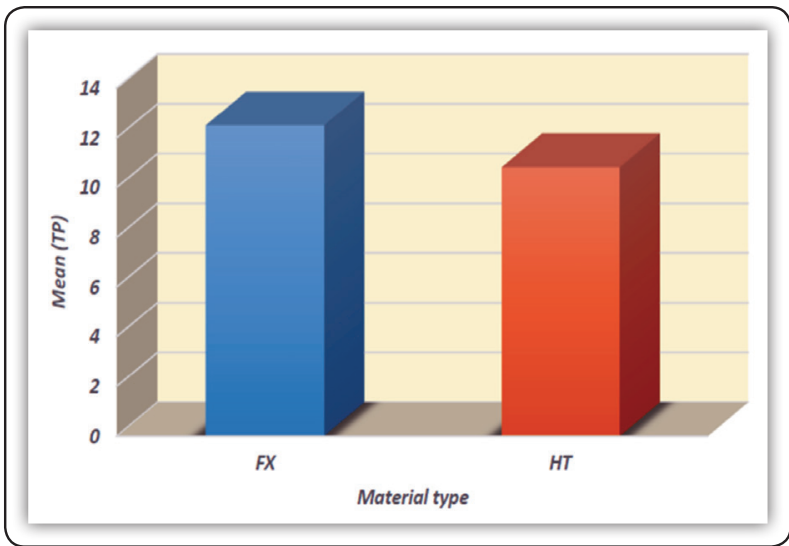

FIG (1) A column chart presenting mean TP values as a function of material type.

The same order was observed with the three thicknesses of the HT group, with the $0.5 \mathrm{~mm}$ subgroup recording the statistically significant $\left(\mathrm{P}=0.0001^{*}\right.$
$<0.05)$ highest mean TP value $(\mathrm{TP}=12.82 \pm 1.46)$, followed by the $1 \mathrm{~mm}$ subgroup ( $\mathrm{TP}=10.68 \pm 1.66$ ), whereas the statistically significant lowest TP value was recorded with the $1.5 \mathrm{~mm}$ subgroup $(\mathrm{TP}=$ $8.68 \pm 2.12)$. Inter-group comparisons were made to compare mean TP values of each thickness of the two zirconia ceramic materials. It was found that each thickness of the FX group recorded a statistically significant higher mean TP value compared to the same thickness of the HT group. Data of both intra- and inter-group comparisons are presented in table (2) and figure (2).

TABLE (2) Comparison of translucency parameter (TP) results $(M e a n \pm S D)$ between both groups as a function of thickness.

\begin{tabular}{|c|c|c|c|c|}
\hline \multirow{2}{*}{ Variables } & \multicolumn{3}{c|}{ Thickness (mm) } \\
\cline { 3 - 5 } & 0.5 & 1 & 1.5 \\
\hline \multirow{2}{*}{ FX } & Mean \pm SD & $\begin{array}{c}15.51^{\mathrm{Aa}} \\
\pm 1.99\end{array}$ & $\begin{array}{c}13.12^{\mathrm{Ba}} \\
\pm 2.374\end{array}$ & $\begin{array}{c}10.46^{\mathrm{Ca}} \\
\pm 3.06\end{array}$ \\
\hline \multirow{2}{*}{ HT } & Mean \pm SD & $\begin{array}{c}12.82^{\mathrm{Ab}} \\
\pm 1.46\end{array}$ & $\begin{array}{c}10.68^{\mathrm{Bb}} \\
\pm 1.66\end{array}$ & $\begin{array}{c}7.79^{\mathrm{Cb}} \\
\pm 1.61\end{array}$ \\
\hline Statistics & P value & $0.003^{*}$ & $0.0158^{*}$ & $0.0249^{*}$ \\
\hline
\end{tabular}

*; significant $(p<0.05)$

Different uppercase letter in rows and lowercase letters in columns denote statistically significant difference.

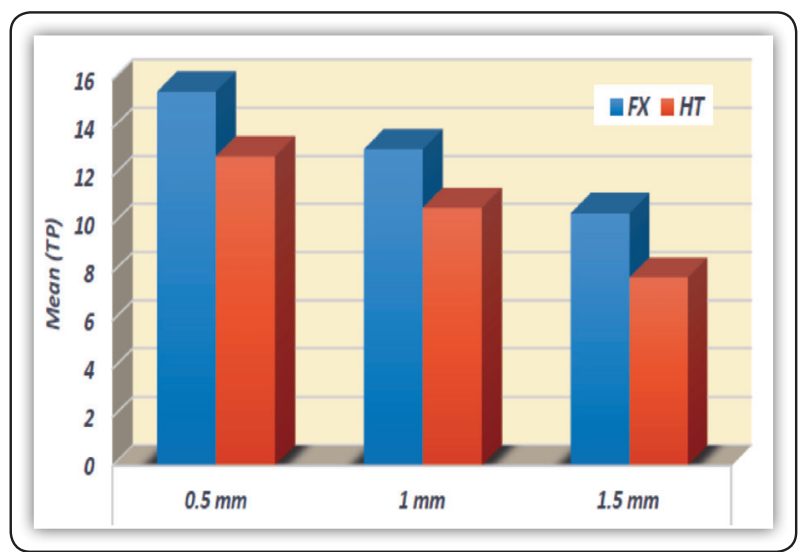

FIG (2) A column chart of presenting mean TP values of the two groups as a function of thickness. 


\section{DISCUSSION}

The increased patients' demand for higher esthetics and more natural-looking restorations has been a strong motive towards the shift to all ceramic dental restorations. Zirconia is at the center if this drive. The hypothesis of this study that thickness decrease will have a significant effect on the translucency of the two types of monolithic zirconia was accepted. For each of the two materials, thickness decrease resulted in an increase the translucency parameter of the zirconia material. The highest mean TP value was recorded with the $0.5 \mathrm{~mm}$ subgroup, followed by the $1 \mathrm{~mm}$ subgroup, whereas the lowest mean TP value was recorded with the $1.5 \mathrm{~mm}$ subgroup. The polycrystalline nature of zirconia can be a main cause in this result. When a light beam passes through a material, crystals within the microstructure of the substance interfere with light passage, deflecting the light beam and leading to increased scattering. This increased scattering and decreased light penetration leads to the less translucent appearance of a more crystalline structure. With the thickness of a zirconia being decreased to $0.5 \mathrm{~mm}$, a favorable decrease in the number of crystals interfering with the passage of light through that restoration can be achieved, with an eventual increase in and enhancement of its translucency.

Although the thickness recommendation of recent high translucent monolithic zirconia ranges from $0.5 \mathrm{~mm}$ as the minimal recommended thickness for a single-unit full coverage dental restoration, to $1 \mathrm{~mm}$ when used as part of multi-unit fixed dental prosthesis, it is increasingly witnessed at clinical practice that dentists replace and old metal-ceramic restoration with a new monolithic all ceramic restoration. The previous invasive tooth preparation of the tooth which had had received a metal-ceramic crown already predetermines the thickness of the new all ceramic replacement. Thus, a thickness of $1.5 \mathrm{~mm}$, both axially and occlusally, is often encountered while fabricating monolithic zirconia replacements. This has made the study of fabricating these recent high translucent zirconia ceramics at that increased thickness of interest. Translucency of both fully-stabilized cubic and partially-stabilized tetragonal zirconia was significantly decreased as a result of this thickness increase. This raises the question of whether monolithic zirconia can perform fairly satisfactory with such an increased thickness when used in the monolithic design.

A comparison of the two zirconia ceramics revealed an increased translucency with the FSZ when compared to PSZ of the same thickness. This result can be attributed to the structural differences and the difference in chemical composition between the two materials. The HT group represents a partially-stabilized tetragonal zirconia, whilst the FX group represents a fully-stabilized cubic zirconia. The FSZ FX group has a higher concentration of yttria ${ }^{(9)}$ as a stabilizing oxide (between $9.15 \%$ and 9.55\%) than the PSZ HT group. This increased yttria content has led to the development of FSZ in which the cubic lattice is the prevalent phase in a zirconia structure ${ }^{(22)}$. The isotropic arrangement and the non-birefringent nature of cubic crystals makes for a more favorable light pathway through FSZ compared to PSZ. An isotropic material is known to allow for the same light diffusion in all directions. The cubic crystallographic lattice gives the two benefits of isotropy -i.e. favorable light penetration in all direction- and non-birefringence. Birefringence, also often described as anisotropy of refraction ${ }^{(23)}$, is the optical property of a material having a refractive index that depends on the polarization and propagation direction of light ${ }^{222}$. This means that the refractive index of a material changes as the direction of light propagation/transmission through that material changes. An anisotropic material is essentially birefringent. The non-birefringent orientation of cubic crystals adds to FSZ microstructural uniformity when a light beam passes through it. 


\section{CONCLUSIONS}

Within the limitation of the current study it can be concluded that: higher translucency can be obtained from fully-stabilized cubic zirconia compared to partially-stabilized tetragonal zirconia. Thickness decrease can enhance and improve the translucency of recent high translucent monolithic zirconia.

\section{REFERENCES}

1. Ghodsi S, Jafarian Z. A review on translucent zirconia. Eur J Prosthodont Restor Dent. 2018 May; 26(2):62-74.

2. Karci M, Demir N. Effect of home bleaching on the translucency of CAD/CAM systems. J Prosthodont. 2019 Mar; 28(3):310-4.

3. Nakonieczny DS, Ziębowicz A, Paszenda ZK, Krawczyk C. Trends and perspectives in modification of zirconium oxide for a dental prosthetic applications - A review. Biocyber Biomed Eng. 2017; 37(1):229-45

4. Nistor L, Grădinaru $\quad \mathrm{M}$, Rîcă $\quad \mathrm{R}$, Mărășescu $\quad \mathrm{P}, \mathrm{Stan}$ $\mathrm{M}$, Manolea $\mathrm{H}$ et al. Zirconia use in dentistry - manufacturing and properties. Curr Health Sci J. 2019 Mar; 45(1):28-35.

5. Özkurt-Kayahan Z. Monolithic zirconia: A review of the literature. Biomed Res 2016; 27(4):1427-36.

6. Abdelbary O, Wahsh M, Sherif A, Salah T. Effect of accelerated aging on translucency of monolithic zirconia. Future Dent J. 2016; 2:65-9.

7. Nakamura K, Harada A, Inagaki R, Kanno T, Niwano Y, Milleding P, et al. Fracture resistance of monolithic zirconia molar crowns with reduced thickness. Acta Odontol Scand 2015; 73:602-8.

8. Bayindir F, Koseoglu M. The effect of restoration thickness and resin cement shade on the color and translucency of a high-translucent monolithic zirconia. J Prosthet Dent. 2019 Apr; 23(18):103-9.

9. Alraheam IA, Donovan T, Boushell L, Cook R, Ritter AV, Sulaiman TA. Fracture load of two thicknesses of different zirconia types after fatiguing and thermocycling. J Prosthet Dent. 2019 Aug 2.

10. Sen N, Isler S. Microstructural, physical, and optical characterization of high translucency zirconia ceramics. J Prosthet Dent. 2019 Aug 2.
11. Shahmiri RA, Standard OC, Hart JN, Sorrell CC. A review of the characteristics and optimization of optical properties of zirconia ceramics for aesthetic dental restorations. Int Scholar Sci Res Innov. 2017; 11(8):499-508.

12. Putra A. Effect of hydrothermal treatment on light transmission of translucent zirconias. J Prosthet Dent. 2017 Sep; 118(3):422-9.

13. Ebeid K, Wille S, Hamdy A, Salah T, El-Etreby A, Kern $\mathrm{M}$. Effect of changes in sintering parameters on monolithic translucent zirconia. Dent Mat. 2014; 30(12):419-24.

14. Kurtulmus-Yilmaz S, Ulusoy M. Comparison of the translucency of shaded zirconia all-ceramic systems. J Adv Prosthodont. 2014 Oct; 6(5):415-22.

15. Johnston W. Review of translucency determinations and applications to dental materials. J Esthet Restor Dent. 2014 Jul-Aug; 26(4):217-23.

16. Sen N, Us YO. Mechanical and optical properties of monolithic CAD-CAM restorative materials. J Prosthet Dent. 2018 Apr; 119(4):593-9.

17. Subasi MG, Alp G, Johnston WM, Yilmaz B. Effect of thickness on optical properties of monolithic CAD-CAM ceramics. J Dent. 2018 Apr; 71:38-42.

18. Silva LH, Lima E, Miranda RBP, Favero SS, Lohbauer U, Cesar PF. Dental ceramics: a review of new materials and processing methods. Braz Oral Res. 2017 Aug; 31(58):133-47.

19. Güth JF, Stawarczyk B, Edelhoff D, Liebermann A. Zirconia and its novel compositions: what do clinicians need to know. Quintessence Int. 2019; 50(7):512-20.

20. Shahmiri R, Standard OC, Hart JN, Sorrell CC. Optical properties of zirconia ceramics for esthetic dental restorations: A systematic review. J Prosthet Dent. 2018 Jan; 119(1):36-46.

21. Marta Fornabaio M, Reveron H, Adolfsson E, Montanaro L, Chevalier J, Palmero P. Design and development of dental ceramics: Examples of current innovations and future concepts. Adv Ceram Biomater. 2017; Ch.11:355-89.

22. Zhang Y. Making yttria-stabilized tetragonal zirconia translucent. Dent Mater. 2014 Oct; 30(10):1195-203.

23. Mehta SB, Shribak M, Oldenbourg R. Polarized light imaging of birefringence and di-attenuation at high resolution and high sensitivity. J Opt. 2013 Sep; 15(9):1-22. 